\title{
Revolutionizing an accelerated baccalaureate nursing curriculum
}

\author{
Caroline Porr, Andrea Brennan-Hunter, Renee Crossman, Karen Parsons \\ School of Nursing, Memorial University of Newfoundland, Newfoundland \& Labrador, Canada. \\ Correspondence: Caroline Porr. Address: 300 Prince Philip Drive, St. John's, Newfoundland \& Labrador, Canada. \\ Email: cporr@mun.ca
}

Received: March 21, 2014

Accepted: June 15, $2014 \quad$ Online Published: July 29, 2014

DOI : 10.5430/jnep.v4n9p183

URL: http://dx.doi.org/10.5430/jnep.v4n9p183

\begin{abstract}
Students enrolled in accelerated baccalaureate nursing programs have often proven themselves to be independent, ambitious and self-motivated. Nurse educators are being challenged to adapt their accelerated program curricula, teaching approaches and delivery modes to accommodate the goals, abilities and resources of these adult learners. At the same time, the rapid changes occurring in health care delivery, locally and worldwide, challenge new practitioners to quickly achieve an increasing list of cognitive and psychomotor competencies for effective nursing practice. Since January 2011, faculty members of Memorial University School of Nursing have been engaged in a comprehensive initiative to create a new accelerated program with a redesigned curriculum. Briefly presented are key milestones accomplished to date, including articulating the new accelerated program mission statement; determining applicant requirements; formulating a new educational philosophy; seeking governance approval; establishing program outcomes; and, framing the curriculum structure.
\end{abstract}

\section{Key words}

Curriculum design, Learning environments, Pedagogy

\section{I ntroduction}

Forty-eight percent of Canadian schools of nursing offer one or more fast-track or accelerated programs. The accelerated option enables students to complete their nursing education in less time than traditional programs with the benefits of rapid entry into the workforce and less financial burden ${ }^{[1]}$. Students in accelerated nursing programs are predominantly 'Millennials', born in the 1980s and 1990s, who prefer flexibility, creativity, infusion with technology and visual multimedia sources, in content delivery methods ${ }^{[2-4]}$. Millennials, also known as Gamers, Echo Boomers, and the Net Generation ${ }^{[4]}$ are, usually, highly motivated and often have more knowledge and life experiences to bring to the classroom than traditional nursing students. Current curriculum models and traditional styles of teaching are not always the appropriate fit for Millennials if there is minimal learner engagement, autonomy, critical reflection, and social connection through technology ${ }^{[2,4,5]}$.

Since its inception in 2002, the accelerated program at Memorial University School of Nursing (MUNSON) has been a 24-month compressed version of the four-year baccalaureate program. Most students in the accelerated option have held a previous university degree while $20 \%$ of enrolled students have had advanced standing. The School's accelerated program 
has been evaluated and modified within the confines of existing structures to address concerns identified by faculty and graduates. Despite changes, however, many of the challenges have remained, including too much content delivered in short timeframes, limited opportunity for student deliberation and reflection, and insufficient 'down time' between sequential course blocks.

In January 2011, MUNSON faculty gathered during a two-day workshop to discuss the need for creation of a new accelerated program. This need was based on evaluations of the existing program and the urgency was further incited by the Future of Nursing report published by the Institute of Medicine (IOM). The IOM ${ }^{[6]}$ recommended improvements to the entire nursing education system in order for graduates to be equipped with requisite competencies to deliver high quality care to patients who are increasingly more acute and complex. Requisite competencies covering leadership, health policy, system improvement, research, evidence-based practice, team work, and collaboration should be integrated into curricula. Also, according to the IOM ${ }^{[5]}$, practice domains such as community health, public health and gerontology should be given great emphasis.

During the two-day workshop, faculty also discussed empirical findings from the Carnegie Foundation National Study of Nursing Education ${ }^{[7]}$ which concluded students are not prepared to critically reason their way through complex clinical situations and prioritize salient patient needs. Nurse educators across North America have been advised to shift from teaching abstract theoretical concepts to focusing on pedagogic strategies that stimulate nursing students to apply concepts in contextually-rich learning environments. The classroom setting must be altered such that "students are absolutely engaged because they know they are rehearsing for their practice" ${ }^{\text {[7, p. 59] }}$. Student engagement is one of many recommenddations for transforming prelicensure nursing education to prepare nursing students for current health care delivery systems, shifting population demographics, scientific advancements, and the knowledge explosion ${ }^{[8]}$.

\section{The curriculum redesign process}

Plans to create a new accelerated baccalaureate nursing program at MUNSON with a redesigned curriculum were launched with enthusiasm. Faculty members were excited because they were about to 'revolutionize' both the curriculum and the way they teach nursing students. The process of curriculum redesign remains a work-in-progress (see Figure 1) but to date several key milestones have been achieved, including: 1) articulating the program mission statement; 2) determining applicant requirements; 3) formulating a new educational philosophy; 4) seeking governance approval; 5) establishing a comprehensive list of graduate proficiencies which would become the program outcomes; and, 6) framing the curriculum structure. The last milestone listed (framing the curriculum structure) is the final and current stage in the process of curriculum redesign. Undoubtedly, framing the curriculum structure is proving to be the most labor-intensive as we are determining course objectives, expected observable behaviors of students, learning activities, and evaluative components for each course in the new curriculum.

\section{Milestone 1: Articulating the program mission statement}

Interested faculty assembled to form an ad-hoc Bachelor of Nursing as a Second Degree (BNSD) Program Committee. In addition, an instructional development consultant from the university's Faculty of Education joined the Committee to provide pedagogical, curricular and faculty support. The first task for the Committee was to identify "what the new accelerated baccalaureate nursing program needs to be.” Following a series of discussions, three lists emerged: 1) desired qualities of the new program; 2) desired attributes and abilities of the graduates; and, 3) desired requirements of the applicants. Collectively, these lists became the basis for the mission statement:

The Bachelor of Nursing as Second Degree program will prepare entrants to become competent and compassionate nurses to meet holistic health concerns of individuals, families, groups and communities within a rapidly evolving health care system. Through active engagement in a cohesive, integrated, contextually-relevant curriculum, graduates will demonstrate competence in the delivery of nursing care, including professional accountability, communication, critical reasoning, leadership and self-directed learning. 


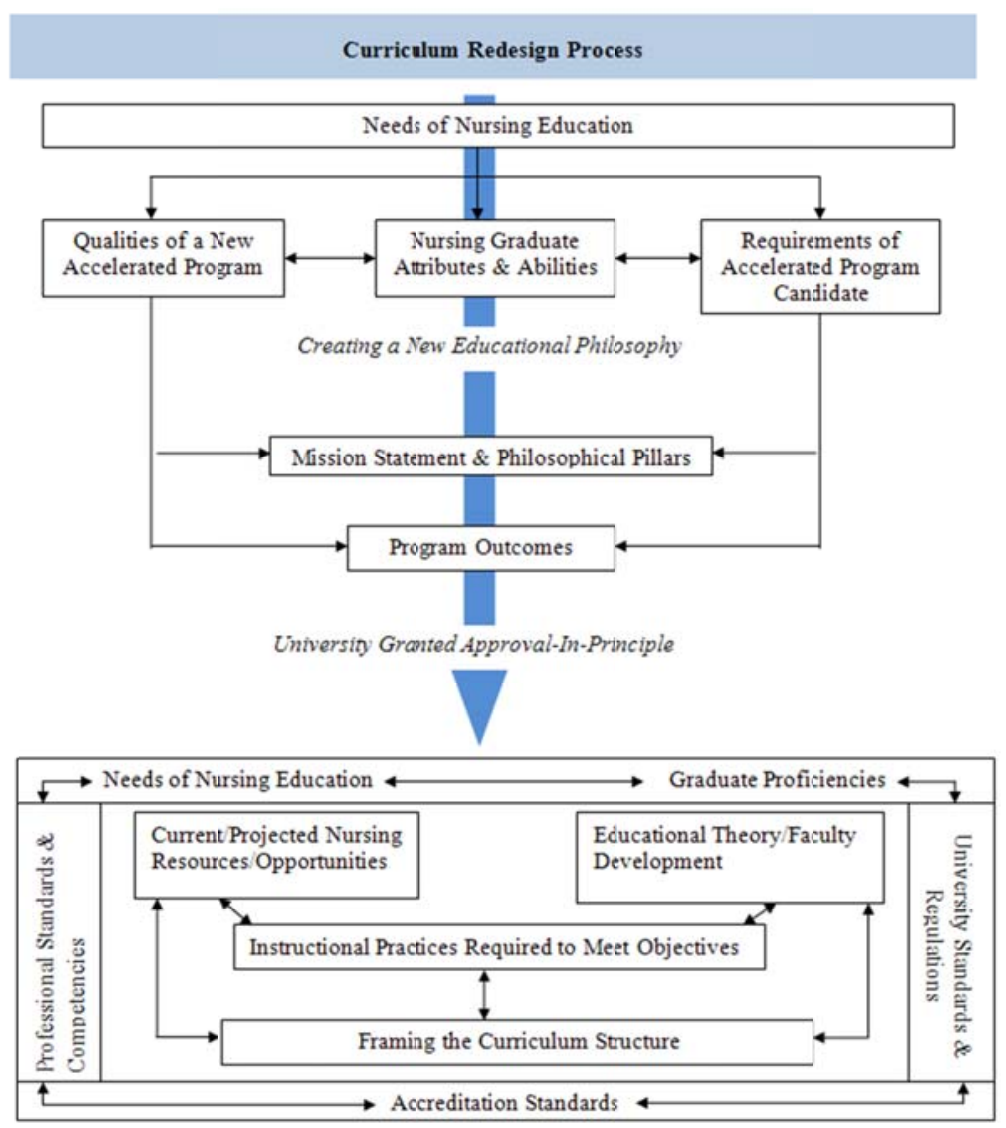

Figure 1. Schematic of the curriculum redesign process of the new BNSD program

\section{Milestone 2: Determining applicant requirements and outlining the application process}

The BNSD Program Committee was briefly restructured into two committees: Committee I would tackle applicant requirements, and Committee II would tackle the program's educational philosophy. Committee I took the lists formulated during the earlier discussions to determine the criteria for admission screening and acceptance into the program and to complete, as appropriate, the required steps to implement the new entry requirements and prerequisites (see Table 1). A key aspect of Committee I's work was to make information about the new program and resources available to potential candidates, especially during BNSD program development and implementation stages. Unique to this new program would be an interactive web-based module to provide applicants with information about the roles and responsibilities of nurses as well as expectations of students in the BNSD program. Candidates would be expected to complete this module as part of the application process. A comprehensive interview screening process was also proposed.

Table 1. Academic Requirements of BNSD Program Applicants

\begin{tabular}{ll}
\hline Requirement & Comments \\
\hline Bachelor's Degree & $\begin{array}{l}\text { Must have a Bachelor's Degree from a recognized university. } \\
\text { Gust have achieved a cumulative grade point average of at least 3.0 on a 4-point scale in their degree } \\
\text { Statistics }\end{array}$ \\
$\begin{array}{l}\text { Biochemistry } \\
\text { Microbiology }\end{array}$ & $\begin{array}{l}\text { Requires evidence of successful completion of three credit hours. } \\
\text { Requires evidence of successful completion of three credit hours. }\end{array}$ \\
$\begin{array}{l}\text { Anatomy and } \\
\text { Physiology }\end{array}$ & $\begin{array}{l}\text { Requires evidence of successful completion of three credit hours in Anatomy and three credit hours in } \\
\text { Physiology, or a combined six-credit-hour course in Anatomy and Physiology. }\end{array}$ \\
\hline
\end{tabular}




\section{Milestone 3: Formulating a new educational philosophy}

Temporary restructuring of the large committee enabled two sub-committees to work concurrently on the program's applicant requirements or the program's educational philosophy. Committee II deliberated to create a new educational philosophy and was responsible for identifying the philosophical pillars or principles that would both anchor and propel the new BNSD program—learning in context, professionalization and self-direction (see Figure 2).

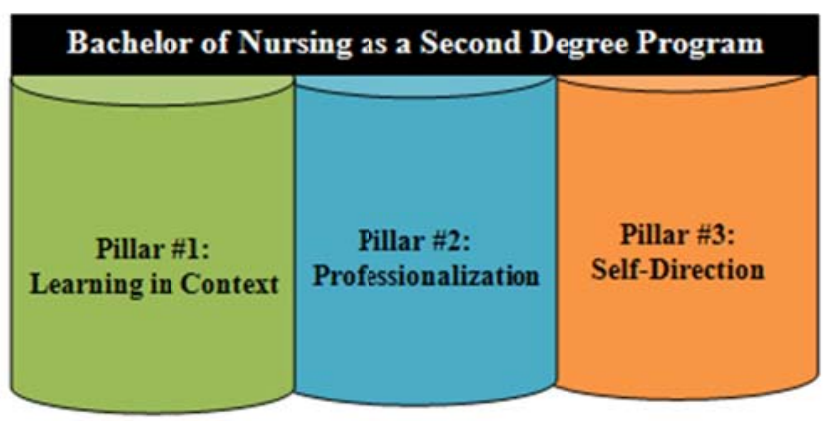

Figure 2. The new BNSD program is founded on an educational philosophy comprised of three pillars

Learning in context refers to the opportunity afforded all students to develop nursing expertise while addressing real-life situations. A comprehensive integrative design with coordinated clinical, laboratory, and classroom experiences will enable students to actively apply developing knowledge and skills within relevant patient care learning environments. Immediate application of evidence-based knowledge and skills within contextually-relevant learning environments will enable students to acquire the sensibilities and cognitive and psychomotor competencies necessary to thrive in rapidly changing systems of health care delivery. Realistic scenarios for student learning will develop students' capacity to prioritize and to critically analyze salient aspects of practice situations whether the patient is an individual, family, group, or community. An example of learning in context may also include high fidelity simulation ${ }^{[9]}$ in the learning resource center and case-based or simulated role playing in the classroom. Students, for example, could engage in the application of health promotion concepts and skills through a simulated activity. Groups of students would be assigned to teach the rest of their classmates about a topic or health concern for a chosen age aggregate. Groups choose the age aggregate, the health topic as well as the teaching strategies, and then 'teach' their classmates. Classmates would role-play the chosen age aggregate and then after the teaching session evaluate the group’s teaching effectiveness.

To become competent practitioners, nursing students require learning opportunities that facilitate engagement in meaningful activities as opposed to memorizing facts as passive recipients of knowledge ${ }^{[10]}$. Experiential learning such as the health promotion teaching example, above, equips graduates to 'learn on the fly' ${ }^{[11,12]}$. Nurse educators must do more to underscore the myriad of health care complexities that new graduate nurses will face as they enable nursing students to learn 'how to be a nurse' ${ }^{[12]}$. Context-Based Learning (CBL), which is a hybrid of Problem-Based Learning, has been successful at both exposing students to today's health care climate and situating learning in authentic or realistic environments ${ }^{[13]}$. CBL fosters examination of real-life complex health care situations; self-directed study; integration of new information; and, critical reflection ${ }^{[14]}$.

The process of professionalization is a key component of the BNSD program from 'Day One'. Professionalism (including professional demeanor, conduct and communication) is also an indicator of "Professional Accountability", one of the Program Outcomes (see Table 2), and will be the expectation in all learning environments (classroom, laboratory simulation and practicum rotations) and health care settings. It is the responsibility of nurse educators, staff and students to model the qualities desired in graduate nurses. Nurse educators will foster a culturally safe and respectful learning environment wherein students experience full respect, support and acknowledgment for their successes and achievements. 
In turn, students are expected to increasingly acknowledge and demonstrate respect for the perspectives, values, and experiences of their fellow students, faculty, and their patients as they progress through the program.

Table 2. BNSD Program Outcomes and Sub-Outcomes

\begin{tabular}{|c|c|}
\hline Program Outcomes & Sub-Outcomes \\
\hline \multirow{5}{*}{ Professional Accountability } & Ethical/legal practitioner \\
\hline & Professional identity \\
\hline & Responsibility for safety \\
\hline & Holistic nursing care \\
\hline & Compassionate care \\
\hline \multirow{6}{*}{ Communication } & Appropriate verbal, nonverbal and written interpersonal communication \\
\hline & Application of counseling skills \\
\hline & Effective group process skills \\
\hline & Effective communication skills within interprofessional teams \\
\hline & Scholarship in written and presented work \\
\hline & Nurse informatics \\
\hline \multirow{4}{*}{ Critical Reasoning } & Reflective practitioner \\
\hline & Problem solver (personal practice focus) \\
\hline & Research minded \\
\hline & Evidence-based practitioner \\
\hline \multirow{6}{*}{ Leadership } & Leadership capacity \\
\hline & Managerial capacity \\
\hline & Problem solver (system focus) \\
\hline & Coordinator of care \\
\hline & Advocate of professional issues \\
\hline & Change agent \\
\hline \multirow{3}{*}{ Self-Directed Learning } & Spirit of inquiry \\
\hline & Knowledge application \\
\hline & Lifelong learning \\
\hline
\end{tabular}

Self-direction speaks to the student's responsibility to negotiate his or her own path to success in collaboration with nurse educators. In today's dynamic health care environment, health professionals have to keep abreast of ever-changing technologies, expansion of specialized knowledge and cultural diversity. Self-directed learning skills are essential in order to leverage current knowledge; to seek out required knowledge; and, to effectively integrate the two in order to provide high quality care. Faculty will assist students in identifying their learning needs, in the development of strategies to meet those needs, and in aligning students' needs with appropriate expertise and resources as they progress through the program.

\section{Milestone 4: Seeking approval}

At regular intervals, the BNSD Program Committee held consultative sessions and sought multi-level approval of the developing program, beginning with all faculty members of the School of Nursing, which is an important step in creating and launching innovation ${ }^{[15]}$. The School of Nursing's Academic Council has endorsed continued development of the new accelerated baccalaureate nursing program after approving the program mission statement, applicant requirements and educational philosophy. The BNSD Program Committee also consulted with nursing students, nurse clinicians and health care partners through scheduled meetings and through formal conference presentations. Regular updates to stakeholders will be provided as the program develops. Notwithstanding budgetary constraints and other potential institutional priorities arising, it is expected that the School of Nursing, the University and the Government, will provide full endorsement and approval of the BNSD program upon review of the final curriculum and implementation plans. 


\section{Milestone 5: Establishing program outcomes}

The process undertaken has been different than curriculum redesign initiatives completed previously; that is, the focus has been on the outcomes of learning rather than the content to be learned. The outcomes of learning (i.e., program outcomes) have been determined by rigorous examination of practice standards and competencies required for entry-level nursing practice $^{[16,17]}$, and by paying close attention to projected requirements of nursing practice, priorities of the School of Nursing, input from health care partners, and provincial government directives. The BNSD Program Committee developed a comprehensive outcomes document that serves as the curriculum blueprint consisting of five major program outcomes and a number of sub-outcomes (see Table 2). Several behavioral indicators have been developed for each of the program outcomes and sub-outcomes.

\section{Milestone 6: Framing the curriculum structure}

The program outcomes and sub-outcomes are guiding design decisions concerning course blocks, clinical practica and other curricular components. Deliberation about what the curriculum structure should look like to facilitate student achievement of outcomes has been dynamic and intense. Expertise and guidance from the instructional development consultant has been invaluable, especially when considering appropriate learning environments and experiences, and constructive alignment of evaluative strategies. Addressing several key questions has been integral to the redesign process, including:

- What are the implications of structuring the program based on relevant themes (e.g., Human Responses to Disease) instead of a traditional content-based (Medical-Surgical Nursing) organizational framework?

- What contextually-relevant learning opportunities will students be exposed to? Which are essential? Which are enriching but not essential?

- What pedagogic techniques will maximize reflective practice and foster professional responsibility, effective communication, critical reasoning, leadership and self-direction?

\section{Faculty Development: “We're not changing just the curriculum!”}

The program's curriculum revolution has both necessitated and facilitated ongoing faculty development and support. Members of the BNSD Program Committee, in particular, have undergone a paradigmatic shift in thinking as they place responsibility for learning on the learner and strive to foster true student-centered learning ${ }^{[18,19]}$. As nurse educators we have been stepping outside our comfort zones, and, incrementally, altering our pedagogic approaches. We have entered a realm that has been as fascinating and exciting as it has been anxiety-provoking, as reflected by one Committee member:

Magolda ${ }^{[18]}$ likens the teacher-student partnership to a two seated bike. In the traditional model the teacher is on the front and is directing the content. In the Learning Partnerships Model the teacher is still on the bike, but has a slightly different role; more as a facilitator of learning rather than instructor. This was one of the greatest learning experiences for me, one of my greatest shifts in thinking. I am not letting go--I am shifting my grip.

\section{Monitoring and evaluating the new BNSD program}

The process of program development with a revolutionized curriculum has been systematically mapped and is unfolding well. However, as the new accelerated program unfolds with incoming cohorts, it is essential that both formative and summative evaluation methods ${ }^{[20]}$ are implemented to monitor and ensure alliance with the mission, educational philosophy and educational goals. Critically important is ensuring that graduates obtain the competencies required for successful licensure and practice.

The BNSD program evaluation will include continuation of formative and summative strategies already in practice in the School. The School's formative and summative evaluation strategies include conducting student and faculty focus groups 
to obtain feedback, reviewing faculty course reports and course grades, and yearly surveys of graduates and triennial surveys of employers.

In addition, we will test the effectiveness of the BNSD program by distributing questionnaires to students pre- and post-BNSD program implementation. Two evaluation questionnaires have been designed to quantitatively measure the Program's achievements: one questionnaire will be distributed to students at midpoint during the BNSD program, and, the other questionnaire will be distributed just prior to graduation. Each questionnaire is comprised of 48 questions, a pair of questions for each sub-outcome under the five major program outcomes of Professional Accountability, Critical Reasoning, Communication, Leadership, and Self-Directed Learning (see Table 2). The first question asks students to what extent the content or learning experience central to the specified sub-outcome was present within the program. The second question for each sub-outcome measures the extent to which students perceive that they can apply the sub-outcome content or skills to nursing practice. Students will be asked to respond to the questions using a seven-point Likert rating scale. Each class cohort for the year preceding and three years after the inception of the BNSD program will be asked to complete the questionnaires. The results will be analyzed to document effectiveness and identify areas for strengthening the program; and, to direct future development and evaluation.

\section{Conclusion}

The process of revolutionizing the curriculum of the new BNSD program has been comprehensive, challenging, transformative on many levels, and more demanding than originally anticipated. However, the combination of enthusiastic faculty who are willing to 'go outside the box', the full support of administration, and the external guidance from education experts ensures that the vision for a new program and redesigned curriculum will come to fruition. We are hopeful that future program evaluation results will provide the evidentiary support that the new accelerated program and curriculum are benefitting nursing students, faculty; and ultimately, the quality of nursing care services delivery.

\section{References}

[1] Canadian Nurses Association (CNA) \& Canadian Association of Schools of Nursing (CASN). Registered nurses education in Canada Statistics 2010-2011. Registered nurse workforce, Canadian production: Potential new supply. Ottawa, ON: Author. 2012, November. Available from: http://www2.cna-aiic.ca/cna/documents/pdf/publications/NSFS _Report_2010-2011_e.pdf

[2] Cangelosi, P.R., \& Whitt, K.J. Accelerated nursing programs: What we do know? Nursing Education Perspectives. 2005; 26: 113-118. PMid:15921128

[3] Penrose, B., \& Koczara, S. Understanding the experience of accelerated second-degree nursing students and graduates: A review of the literature. The Journal of Continuing Education in Nursing. 2009; 40(2): 74-78. http://dx.doi.org/10.3928/00220124-20090201-08

[4] Yoder, S.L., \& Terhorst II, R. "Beam me up, Scotty”: Designing the future of nursing professional development. The Journal of Continuing Education in Nursing. 2012; 43(10): 456-462. PMid:22966774 http://dx.doi.org/10.3928/00220124-20120904-78

[5] Walker, C.M., Tilley, D.S., Lockwood, S., \& Walker, M.B. An innovative approach to accelerated baccalaureate education. Nursing Education Perspectives. 2008; 29(6): 347-352. PMid:19244800

[6] Institute of Medicine. (IOM). The future of nursing: Leading change, advancing health. Washington: The National Academic Press; 2011.

[7] Benner, P., Sutphen, M., Leonard, V., \& Day, L. Educating nurses: A call for radical transformation. San Francisco: Josey-Bass; 2010.

[8] Hegarty, J., Condon, C., Walsh, E., \& Sweney, J. The undergraduate education of nurses: Looking into the future. International Journal of Education Scholarship. 2009; 6(1): 10-11.

[9] Zulkosky, K.D. Simulation use in the classroom: Impact on knowledge acquisition, satisfaction and self-confidence. Clinical Simulation in Nursing. 2012; 8: e25-e33. http://dx.doi.org/10.1016/j.ecns.2010.06.003

[10] Burrell, L.A. Integrating critical thinking strategies into nursing curricula. Teaching and Learning in Nursing. 2014 ; 9: 53-58. http://dx.doi.org/10.1016/j.teln.2013.12.005 
[11] Forneris, S.G., \& Peden-McAlpine, C.J. Contextual learning: A reflective learning intervention for nursing education. International Journal of Nursing Scholarship. 2006; 3(1): 1-18.

[12] Gazarian, P.K., \& Pennington, M. Clinical teleconferencing: Bringing the patient to the classroom. Nursing Forum. 2012; 47(4): 210-216. PMid:23127234 http://dx.doi.org/10.1111/j.1744-6198.2012.00279.x

[13] Onda, E.L. Situated cognition: Its relationship to simulation in nursing education. Clinical Simulation in Nursing. 2012; 8: e273-e280. http://dx.doi.org/10.1016/j.ecns.2010.11.004

[14] Williams, B., \& Day, R.A. Context-based learning. In Young, L.E. \& Paterson, B.L., (Eds.). Teaching Nursing: Developing a Student-Centered Environment, (pp. 221-224). Philadelphia: Lippincott, Williams and Wilkins; 2007.

[15] Billings, L. Allen, P. Armstron, M., \& Green, A. Creating and launching innovative nursing education programs: Perils and pearls. Nursing Education Perspectives. 2012; 33(5): 292-296. PMid:23061185 http://dx.doi.org/10.5480/1536-5026-33.5.292

[16] Association of Registered Nurses of Newfoundland and Labrador. Competencies in the Context of Entry-Level Registered Nurse Practice (2008-2013). St. John's: Author.

[17] Association of Registered Nurses of Newfoundland and Labrador. Competencies in the Context of Entry-Level Registered Nurse Practice (2013-18). St. John's: Author.

[18] Magolda, M.B. Building learning partnerships. Change: The Magazine of Higher Learning. 2012; 44(1): 32-38. http://dx.doi.org/10.1080/00091383.2012.636002

[19] Young, L.E., \& Maxwell, B. Student-centered teaching in nursing: From rote to active learning. In L.E. Young \& B.L. Paterson, (Eds.). Teaching nursing: Developing a student-centered learning environment, (pp. 3-25). Philadelphia: Williams \& Wilkins; 2007.

[20] Thompson, J.L. Mallet-Boucher, M.. McCloskey, C. Tamlyn, K. \& Wilson, K. Educating nurses for the twenty-first century abilities-based outcomes and assessing student learning in the context of democratic professionalism. International Journal of Nursing Education Scholarship. 2013; 10(1): 219-226. PMid:24106256 http://dx.doi.org/10.1515/ijnes-2013-0031 